\title{
Tradeoff between Narrowing Optical Band Gap and Enhancing Electrical Conductivity of the Metal Nanoparticles-Modified Titanium Oxide Films
}

\author{
Aung Chan Thar ${ }^{1}$, Thaung Hlaing Win ${ }^{2}$, Nyein Wint Lwin ${ }^{1}$ and Than Zaw Oo* \\ 1. Department of Physics, University of Mandalay, Mandalay 100103 Myanmar \\ 2. Department of Physics, Yadanabon University, Mandalay 100103, Myanmar
}

\begin{abstract}
The n-type semiconducting titanium oxide thin films are well-known as electron transporting interlayer in photovoltaic cells. The favorable characteristics of interlayers in photovoltaics are high optical transmittance (T\%), wide band gap energy $\left(\mathrm{E}_{\mathrm{g}}\right)$ and high electrical conductivity $(\sigma)$. Modifying titanium oxide films with metal nanoparticles would increase electrical conductivity but reduce optical band gap energy. We developed the sol-gel derived titanium suboxide $\left(\mathrm{TiO}_{\mathrm{x}}\right)$ films modified with silver $(\mathrm{Ag})$ or gold $(\mathrm{Au})$ or copper $(\mathrm{Cu})$ nanoparticles $(\mathrm{NPs})$. This study explores a tradeoff between narrowing optical band gap and enhancing electrical conductivity of nanostructured $\mathrm{TiO}_{\mathrm{x}}$ films by controlling the $\mathrm{Au}-$ or $\mathrm{Ag}$ - or $\mathrm{Cu}-\mathrm{NPs}$ loading concentrations (mol\%) in titania. The $\mathrm{Au}$ - and $\mathrm{Cu}-\mathrm{NPs}$ loading concentration of $4 \mathrm{~mol} \%$ should meet a tradeoff which yields the higher $\mathrm{T} \%$, wider $\mathrm{E}_{\mathrm{g}}$ and higher $\sigma$ compared to those of pure $\mathrm{TiO}_{\mathrm{x}}$ films. In addition, since the pure $\mathrm{Cu}$ is not thermodynamically stable in ambience as compared to $\mathrm{Au}$ and Ag, the stability of as-obtained colloidal CuNPs is also examined. A careful examination of the time evolution of surface plasmon resonance (SPR) bands of CuNPs indicates that their stability is only up to $4 \mathrm{~h}$.
\end{abstract}

Key words: Titanium suboxide, metal nanoparticles, electrical conductivity, band gap energy.

\section{Introduction}

Titanium dioxide is a wide band gap n-type semiconductor which is chemically stable, nontoxic and biocompatible. Due to its wide-ranging chemical and physical properties, it becomes a subject of intensive research and can be exploited in many potential applications. In organic photovoltaics, it is promising as electron transport layer and optical spacer inserted between cathode and light absorber layer $[1,2]$. It offers several advantages: ease of fabrication, sensitive charge selectivity (inject electrons and block holes) and effective shield against oxygen. Combining the optical and electrical benefits stemming from the incorporation of titanium oxide interlayer, the efficiency of organic photovoltiac devices is greatly enhanced [1-4]. Interlayers in

\footnotetext{
*Corresponding author: Than Zaw Oo, Ph.D., lecturer, research fields: materials science and engineering. E-mail: thanzawoo06@gmail.com; than0031@e.ntu.edu.sg.
}

photovoltaics have the huge impacts on interfacial properties inside the device which range from simple wettability to electronic energy modification [5]. The properties of interlayers can be tailored by incorporating dopants/additives in interlayer materials.

Metal nanoparticles (AgNPs, AuNPs and CuNPs) can be incorporated as dopants into interlayer materials to improve the optical and electrical properties of interlayer itself and light harvesting (optical) properties of nearby light absorber layer in photovoltaics via the phenomenon of surface plasmonics [6-8]. The favorable properties of interlayers are wide band gap, high optical transmittance and high electrical conductivity. Despite achieving higher electrical conductivity in the NPs-integrated interlayer, integration of NPs enables to reduce the band gap of interlayer by creating sub-band states within the band gap of host materials [9]. In the cases (like interlayer in photovoltaics) that 
necessitate both high electrical conductivity and wide optical band gap, it is crucial to explore a tradeoff between narrowing band gaps and enhancing electrical conductivity of nanocomposite interlayers.

Despite more interest in CuNPs for their cost-effectiveness as compared to AgNPs and AuNPs, CuNPs synthesized in ambience inevitably have surface oxide layers and can severely aggregate without proper protection [10]. It is thus crucial to examine the stability of CuNPs and to find ways to improve it by circumventing the problems of oxidation and aggregation. Capping the NPs with a suitable protective layer would be one approach for stability enhancement. In this work, the $\mathrm{AgNPs} / \mathrm{TiO}_{x}$, AuNPs $/ \mathrm{TiO}_{\mathrm{x}}$ and $\mathrm{CuNPs} / \mathrm{TiO}_{\mathrm{x}}$ composite films were fabricated by solution-processable route. Varying the NPs loading concentrations in titania, a tradeoff between two opposing characteristics was extracted for nanocomposite interlayer in photovoltaic application. In addition, the stability of CuNPs was examined by studying the time evolution of SPR bands of colloidal CuNPs.

\section{Experimental Section}

Colloidal Ag-NPs, Au-NPs and Cu-NPs solutions were prepared by a chemical reduction method. In the synthesis of colloidal AgNPs, silver nitrate (0.01 M) and polyvinylpyrrolidone $(0.001 \mathrm{M})$ as a stabilizer were separately dissolved in 2-methoxyethonal and mixed together. The mixture solution was stirred at $80{ }^{\circ} \mathrm{C}$ for $20 \mathrm{~min}$. A yellow solution of Ag-NPs colloids was obtained. In the synthesis of colloidal AuNPs, chloroauric acid $\left(\mathrm{HAuCl}_{4} \cdot 3 \mathrm{H}_{2} \mathrm{O}\right)(0.1 \mathrm{mM})$ was mixed with trisodium citrate dihydrate $\left(\mathrm{Na}_{3} \mathrm{C}_{6} \mathrm{H}_{5} \mathrm{O}_{7} \cdot 2 \quad \mathrm{H}_{2} \mathrm{O}\right)(0.04 \mathrm{M})$ in methanol. The mixture was stirred and boiled at $100{ }^{\circ} \mathrm{C}$ for $20 \mathrm{~min}$. The solution color changed from yellow to dark/red within several min. Following the synthesis of colloidal CuNPs [10], the aqueous solutions of copper (II) sulfate pentahydrate $(0.01 \mathrm{M})$ and polyethylene glycol $6000(0.02 \mathrm{M})$ were mixed and stirred vigorously. The solutions of ascorbic acid $(0.02 \mathrm{M})$ (as an antioxidant) and sodium hydroxide $(0.1 \mathrm{M})$ were added to the synthesis solution. Further, a solution of sodium borohydride $(0.1 \mathrm{M})$ (as a main reducing agent) was added to the solution. An instant color changed from yellow to dark/red indicating that the reduction reaction had started at which we started the time-recording for our time evolution study.

The titanium oxide sol-gel was prepared in a three-necked flask $(100 \mathrm{ml})$ attached with a water condenser and nitrogen gas inlet/outlet. The flask was pre-heated and purged with dry $\mathrm{N}_{2}$ to remove moisture inside the flask. The materials: titanium (V) isopropoxide $(5 \mathrm{ml}), 2$-methoxyethanol $(20 \mathrm{ml})$ and ethanolamine $(2 \mathrm{ml})$ were injected into the flask and stirred at $80{ }^{\circ} \mathrm{C}$ under reflux condition in nitrogen environment. After the reaction time of $2 \mathrm{~h}$, it was allowed to cool to room temperature. The $\mathrm{TiO}_{\mathrm{x}}$ solution was yellow in color and diluted with methanol at a volume ratio of 1:150. The $\mathrm{TiO}_{\mathrm{x}}$ solution and colloidal metal NPs solutions with different molar concentrations were mixed for fabrication of $\mathrm{NPs} / \mathrm{TiO}_{\mathrm{x}}$ composite films. Sol-gel derived $\mathrm{TiO}_{\mathrm{x}}$ films were formed by spin-coating the solution at 3,000 rpm and then dried at $100{ }^{\circ} \mathrm{C}$ for 10 min in air. The average film thickness determined by surface profiler (Tencor Alpha step IQ) is $\sim 100 \mathrm{~nm}$. The optical absorption and transmission spectra in the spectral range of 300-900 $\mathrm{nm}$ were acquired using UV-Vis spectrophotometer (Thermo Scientific GENESIS 10S). The baseline scan using a bare glass substrate was taken prior to the measurement. The sheet resistance and electrical conductivity of the films were measured by Van der Pauw four point probe method.

\section{Results and Discussion}

\subsection{Optical Transmittance and Band-Gap Energy of $\mathrm{NPs} / \mathrm{TiO}_{x}$ Composite Films}

We investigated the effect of AgNPs or AuNPs or $\mathrm{Cu}$-NPs loading concentrations ( 2 to $8 \mathrm{~mol} \%$ ) on 

of the Metal Nanoparticles-Modified Titanium Oxide Films

optical transmission and band gap energy of NPs/ $/ \mathrm{TiO}_{x}$ composite films. Fig. 1 shows surface plasmon resonance (SPR) absorption bands of as-obtained AgNPs, AuNPs and CuNPs colloids. The SPR band $\max \left(\lambda_{\max }\right)$ of $\sim 410 \mathrm{~nm}, \sim 520 \mathrm{~nm}$ and $\sim 570 \mathrm{~nm}$ indicates the formation of AgNPs, AuNPs and CuNPs colloids respectively. Fig. 2. presents the optical transmittance (T\%) spectra of $\mathrm{AgNPs} / \mathrm{TiO}_{\mathrm{x}}$, $\mathrm{AuNPs} / \mathrm{TiO}_{\mathrm{x}}$ and $\mathrm{CuNPs} / \mathrm{TiO}_{\mathrm{x}}$ composite films with different NPs loading concentrations. The broad peaks at $480 \mathrm{~nm}$ for $\mathrm{AgNPs} / \mathrm{TiO}_{\mathrm{x}}$ films (Fig. 2a) and at 530 $\mathrm{nm}$ for AuNPs/TiO $\mathrm{x}$ films (Fig. 2b) are more pronounced at higher NPs loading concentrations. These peaks are most likely contributed from the SPR of corresponding NPs. It is observed that the transmittance of $\mathrm{AgNPs} / \mathrm{TiO}_{\mathrm{x}}$ films decreases with increasing AgNPs loading concentrations (Fig. 2a). For the composite films of $\mathrm{AuNPs} / \mathrm{TiO}_{\mathrm{x}}$ and CuNPs/TiO $/{ }_{x}$, the low NPs loading concentrations (2 and $4 \mathrm{~mol} \%$ ) increase $\mathrm{T} \%$ of pure $\mathrm{TiO}_{\mathrm{x}}$ film (Fig. $2 \mathrm{~b}$ and $2 \mathrm{c}$ ) which may be ascribed to increasing number of voids or larger voids within titania domains induced by NPs incorporation.

The band gap energy $\left(E_{g}\right)$ of the materials determines what portion of the solar energies can pass through a window layer or can be absorbed by light absorber layer. The $\mathrm{E}_{\mathrm{g}}$ of the films was calculated using the relation $(\alpha h v)^{1 / n}=\mathrm{A}\left(\mathrm{hv}-\mathrm{E}_{\mathrm{g}}\right.$ ), where, $\alpha$ is the absorption coefficient and hv is the incoming photon energy. The exponent " $n$ " represents the type of transition: $\mathrm{n}=1 / 2$ for direct and $\mathrm{n}=2$ for indirect allowed transition. Since the $\mathrm{TiO}_{\mathrm{x}}$ films being studied were only annealed at $100{ }^{\circ} \mathrm{C}$, they are amorphous for which the band gap energy above $3.4 \mathrm{eV}$ are independent of the transition type [11]. We have taken $n=1 / 2$ and produced the plots of $(\alpha h v)^{2}$ against photon energy (hv) for all films being studied (Fig. 3). When the linear portion of the plot is extrapolated to the point $\alpha=0$, the optical band gap is obtained. Some reports indicated that introducing appropriate dopants can reduce the band gap energy of host materials by generating structural defects which create sub-band states within the band-gap of host materials [9].

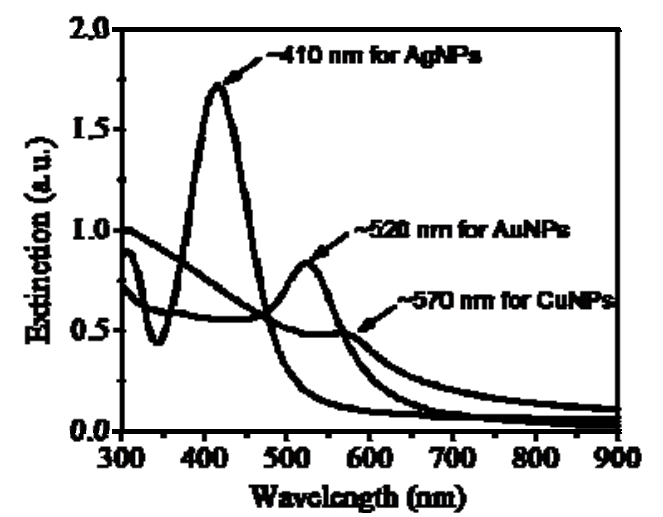

Fig. 1 SPR extinction bands of colloidal AgNPs, AuNPs and CuNPs.

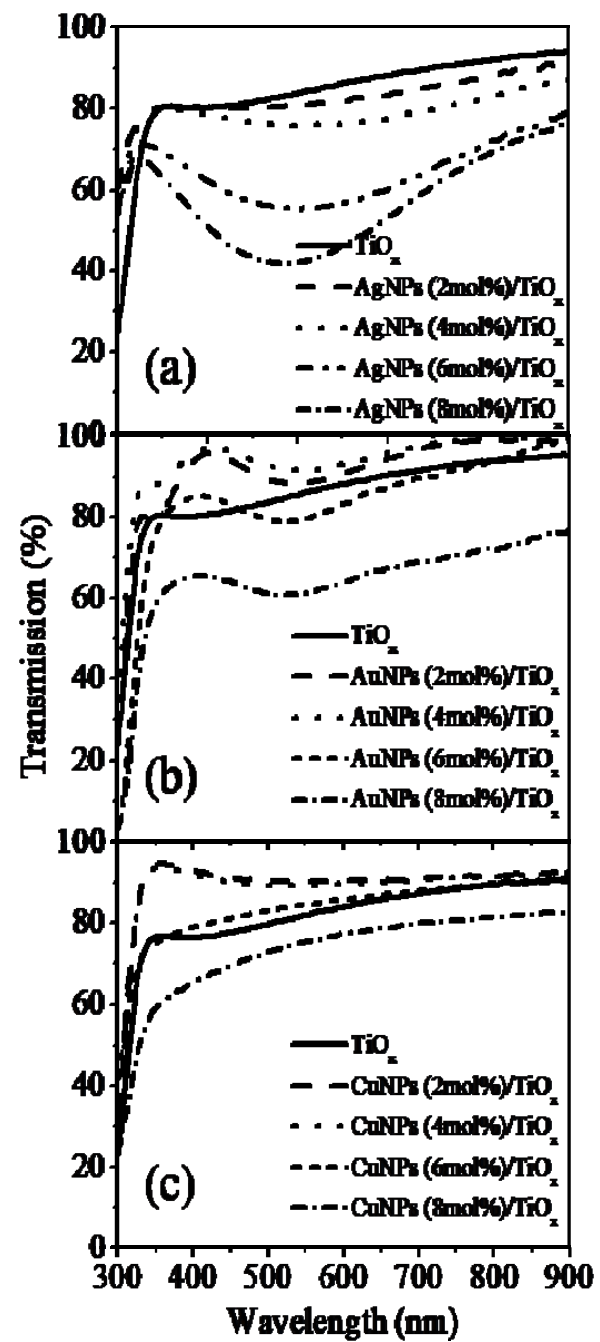

Fig. 2 Optical transmittance spectra of (a) $\mathrm{AgNPs}_{\mathrm{TiO}}$, (b) AuNPs/TiO ${ }_{x}$ and (c) $\mathrm{CuNPs} / \mathrm{TiO}_{\mathrm{x}}$ composite films with different NPs loading concentrations. 

of the Metal Nanoparticles-Modified Titanium Oxide Films

Fig. 4a shows the $E_{g}$ of the composite films as a function of the NPs loadings. It is observed that at the NPs loading of $8 \mathrm{~mol} \%$, the band gap energy reduces to $3.75,3.55$ and $3.75 \mathrm{eV}$ for $\mathrm{AgNPs} / \mathrm{TiO}_{\mathrm{x}}$, AuNPs/TiO ${ }_{x}$ and $\mathrm{CuNPs} / \mathrm{TiO}_{\mathrm{x}}$ films respectively. Whereas the narrower band gap materials are needed for light absorber layer (to enhance photoactivity), wider band gap of the materials is preferred for interlayer (window layer) in photovoltaics.

\subsection{Electrical Conductivity of $\mathrm{NPs} / \mathrm{TiO}_{x}$ Composite} Films

Following the evaluation of optical properties of the films, the electrical conductivities of all composite

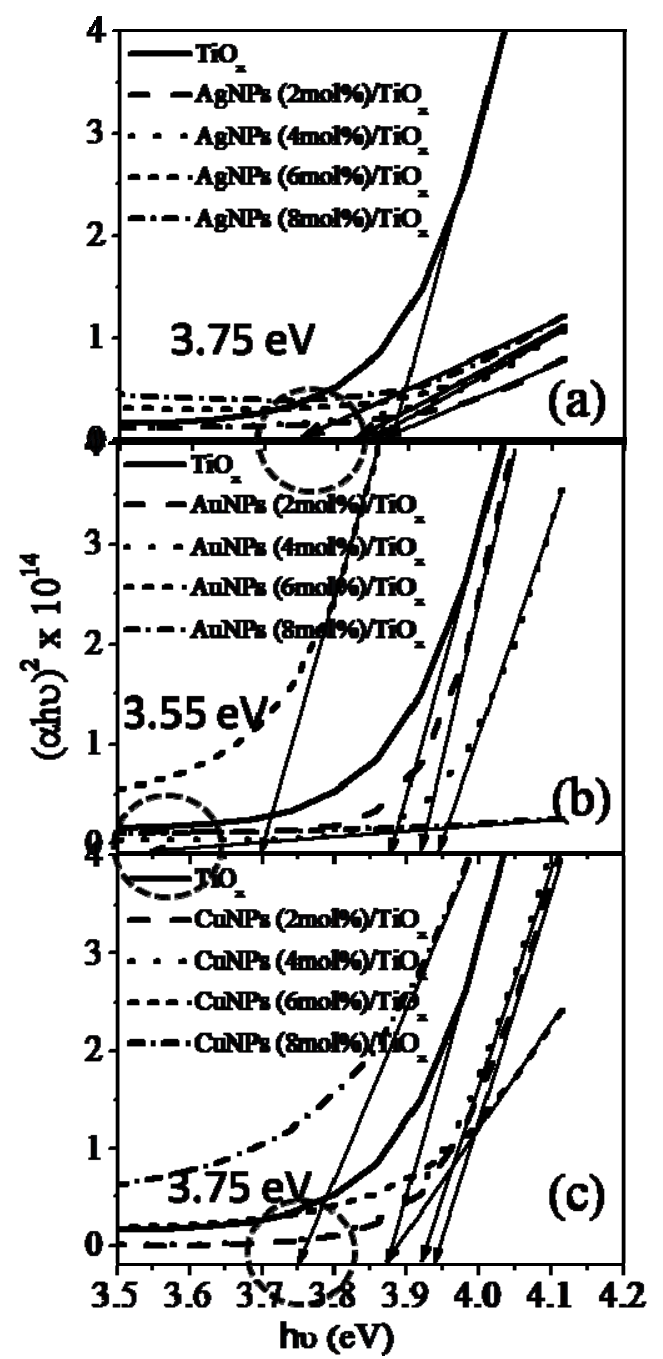

Fig. 3 Plots of $(\alpha h v)^{2}$ against photon energy (hv) for (a) AgNPs/TiO, , (b) AuNPs/TiO ${ }_{x}$ and (c) CuNPs/TiO composite films with different NPs loading concentrations. films with different NPs loadings were determined. The introduction of metal NPs into the host interlayer material would increase electrical conductivity of interlayers by reducing the relatively high resistivity of host titania matrix [12]. The electrical conductivities of $\mathrm{NPs} / \mathrm{TiO}_{\mathrm{x}}$ composite films against NPs loading concentrations are plotted in Fig. 4b. As expected, the electrical conductivities increase with increasing NPs loadings for all NPs/TiO $\mathrm{Tilms}_{\mathrm{x}}$. The conductivity is as high as $1.39,1.27$ and $1.67 \mathrm{~S} / \mathrm{m}$ for AgNPs $/ \mathrm{TiO}_{\mathrm{x}}, \mathrm{AuNPs} / \mathrm{TiO}_{\mathrm{x}}$ and $\mathrm{CuNPs} / \mathrm{TiO}_{\mathrm{x}}$ films respectively at the NPs loading concentration of $8 \mathrm{~mol} \%$.

As seen in Fig. 4, upon increasing NPs loading concentrations, the electrical conductivities keep increasing while the optical band gap energies are band gap energy reduces despite achieving the highest conductivity. Two preferable properties of interlayer could not be attained at the same time. Thus it is rational to explore a tradeoff balancing two opposing characteristics being achieved. Unfortunately we are

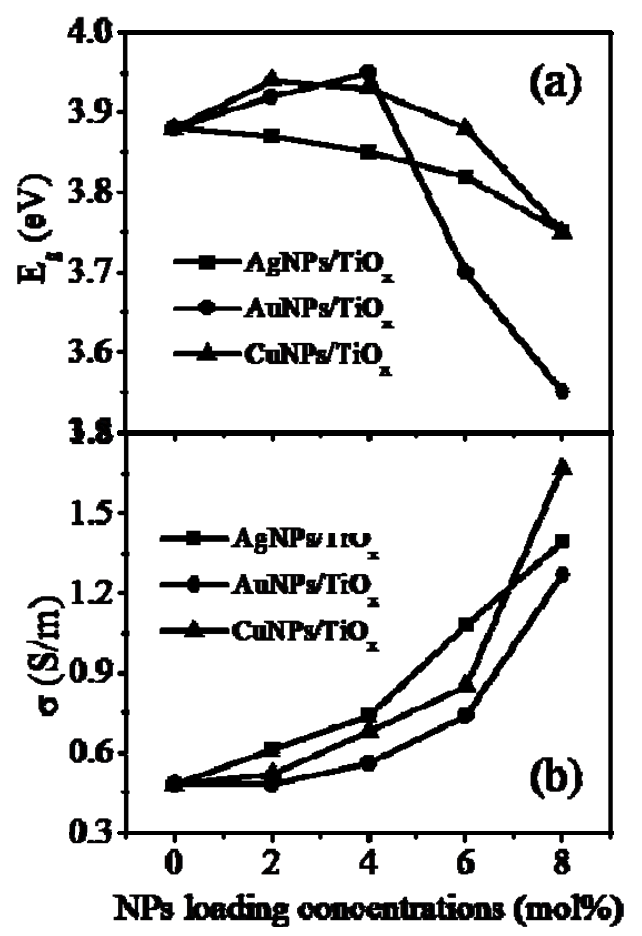

Fig. 4 Plots of (a) optical band gap energy and (b) electrical conductivity against NPs loading concentrations (mol\%) for all composite films. 
fluctuating. At the highest NPs loading of $8 \mathrm{~mol} \%$, the unable to find a tradeoff for $\mathrm{AgNPs} / \mathrm{TiO}_{\mathrm{x}}$ films as the $\mathrm{E}_{\mathrm{g}}$ reduces at all AgNPs loadings. For AuNPs $/ \mathrm{TiO}_{\mathrm{x}}$ and $\mathrm{CuNPs} / \mathrm{TiO}_{\mathrm{x}}$ films, the NPs loading of $4 \mathrm{~mol} \%$ should meet a tradeoff which yields the wider band gap energies $(3.95 \mathrm{eV}, 3.93 \mathrm{eV})$ and higher electrical conductivities $(0.56 \mathrm{~S} / \mathrm{m}, 0.68 \mathrm{~S} / \mathrm{m})$ as compared to those of pure $\mathrm{TiO}_{\mathrm{x}}$ films $(3.88 \mathrm{eV}$ and $0.48 \mathrm{~S} / \mathrm{m})$.

\subsection{Time Evolution of Surface Plasmon Resonance Bands of Colloidal CuNPs}

In order to examine the stability of colloidal CuNPs, time evolution of SPR (Surface plasmon resonance) bands of CuNPs colloids was studied. Fig. 5 shows the SPR extinction spectra of colloidal CuNPs during the record time period up to $4 \mathrm{~h} 45 \mathrm{~min}$. No SPR peak appears within the first record time of $7 \mathrm{~min}$ beyond which it tends to appear indicating the formation of colloidal CuNPs. The SPR peak of as-obtained colloidal CuNPs is at $\lambda \sim 570 \mathrm{~nm}$. SPR peak intensities keep increasing with time in the record time period of 11-40 min and it is invariant in the period of 41-60 min.

This SPR peak position retained at $570 \mathrm{~nm}$ during the record time period 11-60 min (Fig. 5). However, the A careful examination on the acquired extinction spectra indicates that the degree of increase in SPR peak intensity is more pronounced in the period of 11-20 min and gradually slows down in the successive periods of 21-30 min and 31-40 min. The absorption spectra are almost invariant during the interval 1-3 $\mathrm{h}$ (The data are not shown here). The SPR peak positions and intensities remain invariant in the record time period of 3-4 h. However, the tails of the spectra are elevated in the spectral regime beyond $570 \mathrm{~nm}$. Its origin has not yet known. The SPR peak position is red-shifted to $610 \mathrm{~nm}$ after the record time of $4 \mathrm{hr}$. Extending the record time, the peak $(610 \mathrm{~nm})$ is less pronounced and fades away at the recording time of 4 h 45 min implying that the colloidal CuNPs get degraded (oxidized). Observing this time evolution, it

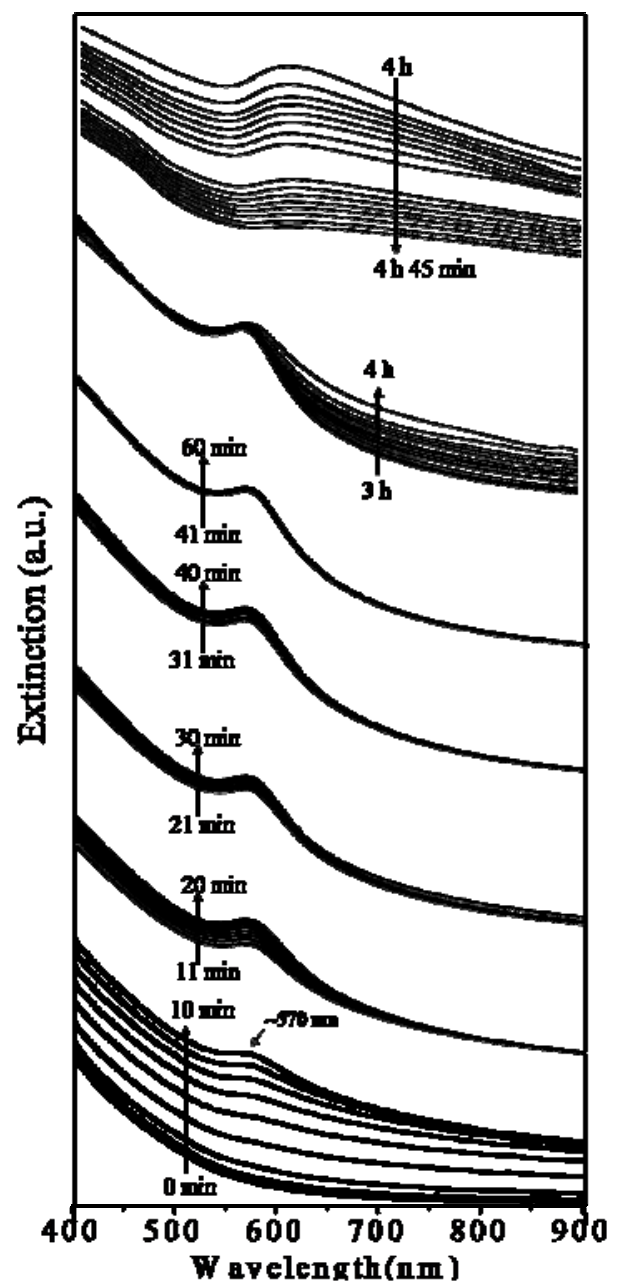

Fig. 5 Time evolution of surface plasmon resonance bands of colloidal CuNPs (record time period $0 \mathrm{~min} \sim 4 \mathrm{hr} 45 \mathrm{~min}$ ). The recording time of $0 \mathrm{~min}$ indicates that the reduction reaction has started.

is found that the stability of CuNPs can only extend up to $4 \mathrm{~h}$.

\section{Conclusions}

The colloidal AgNPs, AuNPs and CuNPs were synthesized by chemical reduction method. The sol-gel derived metal-NPs $/ \mathrm{TiO}_{\mathrm{x}}$ films were fabricated by spin-coating method. Varying NPs loadings in titania, we have extracted a tradeoff which offers a more favorable properties of nanocomposite films for interlayer application in photovoltaics. AuNPs and CuNPs loading of $4 \mathrm{~mol} \%$ should meet a tradeoff which yields the higher electrical conductivity and wider band gap energy as compared to those of pure 
$\mathrm{TiO}_{\mathrm{x}}$ film. The interlayer with high electrical conductivity would promote the charge transport at the electrode interface and the wide band-gap interlayer would transmit the wider range of incoming photon energies into the light absorber layer, thereby increasing the photovoltaic device efficiency.

\section{Acknowledgments}

The authors gratefully acknowledge the research grants supported by University of Mandalay [Project No. 42 (2013-14)].

\section{References}

[1] Waldauf, C., Morana, M., Denk, P., Schilinsky, P., Coakley, K. and Choulis, S. A. et al.. 2006. "Highly Efficient Inverted Organic Photovoltaics Using Solution Based Titanium Oxide as Electron Selective Contact." Appl. Phys. Lett. 89: 233517-9.

[2] Kuwabara, T., Sugiyama, H., Yamaguchi, T. and Takahashi, K. 2009. "Inverted Type Bulk-Heterojunction Organic Solar Cell Using Electrodeposited Titanium Oxide Thin Films as Electron Collector Electrode." Thin Solid Films 517: 3766-9.

[3] Kim, J. Y., Kim, S. H., Lee, H., Lee, K., Ma, W., Gong, X. and Heeger, A. J. 2006. "New Architecture for High-Efficiency Polymer Photovoltaic Cells Using Solution-Based Titanium Oxide as an Optical Spacer." Adv. Mater. 18: 572-6.

[4] Lee, J. H., Cho, S., Roy, A., Jung, H. and Heeger, A. J. 2010. "Enhanced Diode Characteristics of Organic Solar Cells Using Titanium Suboxide Electron Transport
Layer." Appl. Phys. Lett. 96: 163303-5.

[5] Ma, H., Yip, H. -L., Huang, F. and Jen, A. K. -Y. 2010. "Interface Engineering for Organic Electronics." Adv. Funct. Mater. 20: 1371-88.

[6] Lee, J. H., Park, J. H., Kim, J. S., Lee, D. Y. and Cho, K. 2009. "High Efficiency Polymer Solar Cells with Wet Deposited Plasmonic Gold Nanodots." Organic Electronics 10: 416-20.

[7] Kim, S. S., Na, S. I., Jo, J., Kim, D. Y. and Nah, Y. C. 2008. "Plasmon Enhanced Performance of Organic Solar Cells Using Electrodeposited Ag Nanoparticles." Appl. Phys. Lett. 93: 073307-9.

[8] Oo, T. Z., Mathews, N., Xing, G., Wu, B., Xing, B. and Wong, L. H. et al.. 2012. "Ultrafine Gold Nanowire Networks as Plasmonic Antennae in Organic Photovoltaics." J. Phys. Chem. C 116: 6453-8.

[9] Choudhury, B., Dey, M. and Choudhury, A. 2013. "Defect Generation, D-D Transition, and Band Gap Reduction in Cu-doped $\mathrm{TiO} 2$ Nanoparticles." International Nano Letters 3: 25-32.

[10] Dang, T. M. D., Le, T. T. T., Blanc, E. F. and Dang, M. C. 2011. "Synthesis and Optical Properties of Copper Nanoparticles Prepared by a Chemical Reduction Method" Adv. Nat. Sci.: Nanosci. Nanotechnol. 2: 015009-14.

[11] Valencia, S., Marín, J. M. and Restrepo, G. 2010. "Study of the Bandgap of Synthesized Titanium Dioxide Nanoparticles Using the Sol-Gel Method and a Hydrothermal Treatment." The Open Materials Science Journal 4: 9-14.

[12] Kumpika, T., Thongsuwan, W. and Singjai, P. 2012. "Percolation Threshold for Electrical Resistivity of Ag-Nanoparticle/Titania Composite Thin Films Fabricated Using Molecular Precursor Method." J. Mater. Sci. 47: 3890-9. 